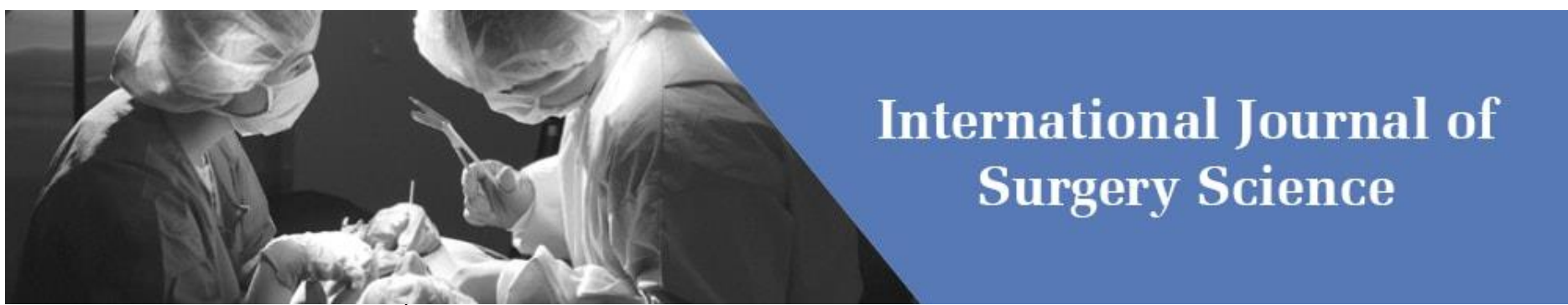

E-ISSN: 2616-3470

P-ISSN: 2616-3462

(c) Surgery Science

www.surgeryscience.com

2021; 5(1): 205-206

Received: 10-12-2020

Accepted: 02-02-2021

Dr. Roy Alban Frank

Assistant Professor, Department of Surgery, Kanachur Institute of

Medical Sciences, Mangalore,

Karnataka, India
Corresponding Author: Dr. Roy Alban Frank Assistant Professor, Department of Surgery, Kanachur Institute of Medical Sciences, Mangalore,

Karnataka, India

\section{An epidemiological study among injury victims seeking service in a tertiary care centre}

\section{Dr. Roy Alban Frank}

DOI: $\underline{\text { https://doi.org/10.33545/surgery.2021.v5.i1d.614 }}$

\section{Abstract}

The patterns of disease and disability and their risk factors, the paying capacity and attitudes of people have changed dramatically in the present scenario. These factors are to be studied and reassessed in a newly comprehensive manner. A new structured study will take advantage of the opportunity to bring global researchers together to communicate and work collaboratively in an environment that is strongly seeking new burden statistics. The epidemiological profile is an essential prerequisite for analysing the public health needs in the country and to enable efficient programme planning and management and this in a country like ours is a boon to have. Mortality is an important indicator of the magnitude of a health problem, along with that; there are several thousand injury survivors who are left with permanent disability.

Keywords: Epidemiology, tertiary care, surgery

\section{Introduction}

The indicator used to quantify the loss of healthy life due to disease is the disability-adjusted life year (DALYs), which includes both the mortality and the morbidity components. Murray and Lopez, 1996, identified five value choices that should be explicitly made ${ }^{[1]}$. How long 'should' people in good health expect to live? This must be decided in order to calculate how many years are lost through death at any given age. How should we compare years of life lost through death with years lived with poor health or disability with various levels of severity? ${ }^{[2]}$ Is a year of healthy life gained now worth more to society than a year of healthy life gained in 20 years' time? ${ }^{[3]}$ Whether lost years of healthy life valued more at some ages than others? Is a year of life at young adult ages valued more than in old age or infancy? ${ }^{[4]}$ Are all people equal? Should these values be determined at local or national level for national level analyses and at national or international level for cross-national comparisons?. The patterns of disease and disability and their risk factors, the paying capacity and attitudes of people have changed dramatically in the present scenario. These factors are to be studied and reassessed in a newly comprehensive manner. A new structured study will take advantage of the opportunity to bring global researchers together to communicate and work collaboratively in an environment that is strongly seeking new burden statistics. The epidemiological profile is an essential prerequisite for analysing the public health needs in the country and to enable efficient programme planning and management and this in a country like ours is a boon to have. Mortality is an important indicator of the magnitude of a health problem, along with that; there are several thousand injury survivors who are left with permanent disability. These nonfatal outcomes must also be measured in order to describe accurately the burden of disease due to injury. Disability is defined as an existing difficulty in performing one or more activities with respect to the subject's age, gender and social role. The basic components of daily living are self-care, social relations and economic activity. Permanent disability such as paraplegia, quadriplegia, loss of eyesight or brain damage can deprive of an individual's ability to do these basic needs. Disabilities force the individuals to depend on others for routine physical care and economical support.

Many studies are necessary to identify and help the people by finding out the factors required for injury control so that the mortality, morbidity and disability can be reduced or rather prevented ${ }^{[5]}$.

Aims and Objectives: To study the epidemiological pattern among injury victims seeking service in a tertiary care centre in the department of Surgery. 


\section{Materials and Methods}

His study was done in the Department of Surgery, Kanachur Institute of Medical Sciences, Mangalore.

Thirty cases that was admitted to the Department were studied in detail and an attempt has been made to report promptly.

Exclusion Criteria: Differently abled who met with accidents.

Inclusion Criteria: All the patients were 20-60 years. This ws done to understand the patterns especially in the working group.

\section{Results}

Table 1: Age Distribution

\begin{tabular}{|c|c|c|}
\hline Number & Mean age & Std. Deviation \\
\hline 30 & 46.27 years & 09.85 years \\
\hline
\end{tabular}

Table 2: Sex Distribution

\begin{tabular}{|c|c|c|}
\hline Number & Male & Female \\
\hline 30 & 23 & 07 \\
\hline
\end{tabular}

Table 3: Co-Morbidities

\begin{tabular}{|c|c|}
\hline Co-Morbidities: & Frequency \\
\hline HTN & 07 \\
\hline DM & 09 \\
\hline DM and HTN & 01 \\
\hline Vertigo & 03 \\
\hline Any other CNS related illness & 05 \\
\hline Any other CVS related illness & 02 \\
\hline Any other Respiratory illness & 01 \\
\hline Muscle Related Illness & 02 \\
\hline
\end{tabular}

Table 4: Parts Injured

\begin{tabular}{|c|c|}
\hline Parts Injured & Frequency \\
\hline Upper Limb & 21 \\
\hline Lower Limb & 24 \\
\hline Head and Neck & 06 \\
\hline Spine & 09 \\
\hline Pelvis & 11 \\
\hline Polytrauma & 28 \\
\hline
\end{tabular}

Table 5: Common Modality of Treatment

\begin{tabular}{|c|c|}
\hline Parts Injured & Frequency \\
\hline Upper Limb & Amputation (1), Compartment syndrome (2) \\
\hline Lower Limb & Amputation (2), Compartment syndrome (3) \\
\hline Head and Neck & 07- Conservative \\
\hline Spine & 09- Conservative \\
\hline Pelvis & Conservative \\
\hline Polytrauma & 28 (Poly care treatment) \\
\hline
\end{tabular}

Table 6: Disability

\begin{tabular}{|c|c|c|}
\hline Disability & Male & Female \\
\hline Temperory & 17 & 06 \\
\hline Permanent & 06 & 01 \\
\hline
\end{tabular}

Table 7: Outcomes

\begin{tabular}{|c|c|c|}
\hline Disability & Male & Female \\
\hline Dead & 01 & 01 \\
\hline Cured & 11 & 06 \\
\hline Diabled & 11 & Nil \\
\hline
\end{tabular}

\section{Discussion}

McBride scale, one of the tools to determine the permanent disability included clinical state of disability at the end of healing period when the part can be used to work. Measurement should be based on the normal for affected limb, disability for specific part and body as a whole and occupational grading of permanent disability to total body for occupation and applicable variant selected from 1 to 9 . There is a rating table, which contains the occupation and the part to be assessed. The score from grades 1 to 9 are taken accordingly. Now, a new Central Government Disability Scale also came into force in India. Worldwide, nearly 1.2 million deaths occur due to RTA every year and 50 million gets injured. Threequarter of all RTAs occur in individuals aged between 15-45 years and were predominantly men. Additionally, for every death, nearly 20-30 people were likely to be hospitalised also. Physical pain maybe less serious, but more common problem often neglected. Injuries to ankles, knees and the cervical spine can result in chronic physical pain and limit an injured person's physical activity for lengthy periods with emotional anguish. Serious burns, contusions and lacerations can lead to emotional trauma associated with permanent disfigurement that is beyond any economic compensation. The graded schedule of evaluation of disability serves four distinct purposes, to evaluate disability under the compensation law, to evaluate disability in liability cases, to determine relative fitness for rehabilitation and vocational training and job, to determine worthiness of treatment of deformities.

\section{Conclusion}

A fair amount of knowledge of understanding of the different epidemiological pattern among injury victims seeking service in a tertiary care centre is necessary to better understand and develop a quick response team.

\section{References}

1. Mohan D. The road ahead: traffic injuries and fatalities in India. Transportation research and injury prevention program. Delhi: IIT 2004.

2. Baker SP, O'Neill B, Karpf RS et al. The injury fact book. USA: Insurance Institute for Highway Safety 1984, p313.

3. Mock. Guidelines for essential trauma care. WHO 2004. who.int/violence/publications/services.

4. Gururaj G. Injuries in India: a national perspective. Burden of disease in India. National commission on macroeconomics \& health. Ministry of health \& family welfare. Government of India 2005, 325-347.

5. Murray CJL, Lopez AD, Mather CD et al. The global burden of disease 2000 project. Geneva: (Revised) WHO 2001, p36.

6. Australian burden of disease and injury study 1998.

7. European International Union burden of disease and injury study 2000. 